\title{
Recovery, work-life balance and work experiences important to self-rated health: A questionnaire study on salutogenic work factors among Swedish primary health care employees
}

\author{
Lina Ejlertsson $^{\mathrm{a}, \mathrm{b}, *}$, Bodil Heijbel $^{\mathrm{b}}$, Göran Ejlertsson ${ }^{\mathrm{a}, \mathrm{b}}$ and Ingemar Andersson ${ }^{\mathrm{a}}$ \\ ${ }^{a}$ School of Health and Society, Kristianstad University, Kristianstad, Sweden \\ ${ }^{\mathrm{b}}$ Department of Clinical Sciences, Malmö, Faculty of Medicine, Lund University, Malmö, Sweden
}

Received 27 September 2016

Accepted 9 March 2017

\begin{abstract}
.
BACKGROUND: There is a lack of information on positive work factors among health care workers. OBJECTIVE: To explore salutogenic work-related factors among primary health care employees.

METHOD: Questionnaire to all employees $(n=599)$ from different professions in public and private primary health care centers in one health care district in Sweden. The questionnaire, which had a salutogenic perspective, included information on self-rated health from the previously validated SHIS (Salutogenic Health Indicator Scale), psychosocial work environment and experiences, recovery, leadership, social climate, reflection and work-life balance.

RESULTS: The response rate was $84 \%$. A multivariable linear regression model, with SHIS as the dependent variable, showed three significant predictors. Recovery had the highest relationship to SHIS $(\beta=0.34)$, followed by experience of work-life balance $(\beta=0.25)$ and work experiences $(\beta=0.20)$. Increased experience of recovery during working hours related to higher self-rated health independent of recovery outside work.

CONCLUSION: Individual experiences of work, work-life balance and, most importantly, recovery seem to be essential areas for health promotion. Recovery outside the workplace has been studied previously, but since recovery during work was shown to be of great importance in relation to higher self-rated health, more research is needed to explore different recovery strategies in the workplace.
\end{abstract}

Keywords: Positive health, healthy work conditions, employee health, occupational health, health promotion

\section{Background}

Workplace health promotion has been defined as the combined efforts of employers, employees and society to improve the health and well-being of

\footnotetext{
*Address for correspondence: Lina Ejlertsson, Department of Clinical Sciences, Malmö, Faculty of Medicine, Lund University, Jan Waldenströms gata 35, 20502 Malmö, Sweden. E-mail: lina.ejlertsson@med.lu.se.
}

people at work and focuses on the factors associated with safe, motivating and enjoyable work settings $[1,2]$. A health promotion-orientated, sustainable and organization-wide healthy workplace policy is an effective way to develop and maintain a healthy workforce [3].

Employee health has been related to the organization and the social climate at work [4], experiences of positive workplace attributes [5] and sufficient 
time for tasks [6] as well as recovery and work-life balance [7, 8]. Regarding recovery, most studies so far have focused on retrieval of energy outside work settings [9].

Work can influence employees in both positive and negative ways. For many professional groups work may be associated with adverse effects, such as stress and burn out $[10,11]$. The well-being of health care staff is a much discussed subject in many countries. Employees in health service professions are considered to be at high risk of stress-related disorders $[12,13]$, and numerous studies of the work environment experience among nursing staff indicate that job stress as well as job turnover and long-term sick leave are common $[14,15]$.

Poor psychosocial work conditions have been found in primary health care, and this factor prompted the current study. Investigations of primary health care in many countries have highlighted a high level of stress and high job demands as well as poor mental and physical health for many categories of staff $[16,17]$, especially among general practitioners $[18,19,20]$.

The dominant paradigm in work environment research is the biomedical model, with a focus on risk factors and shortcomings. There is still a gap between vision and reality in workplace health promotion, and a difference in approach to work environment research [21]. However, there is research with a more salutogenic approach with focus on positive domains of health [22]. The concept salutogenesis (from lat. salus and genesis; i.e. creating health) sets out from the healthy and from the resources in human beings and environments [23], which can lead to an improved health. Work-related enhancing resources, such as reflective skills, open-mindedness, comprehensive view, flexibility and reinforcements, have been explored in relation to the salutogenic theory [24]. This type of orientation can be found in a small number of studies in hospital care regarding the work experiences and health of the staff [25].

Ever since the WHO health promotion conference in Ottawa, Canada, in 1986 [2], a salutogenic approach has gradually developed. This approach has led to the conclusion that the way we view the world affects our ability to cope with stress and that positive feelings help us cope when we are confronted with negative situations [22].

There is a general lack of information about salutogenic work factors, that are evident in health care settings and especially in primary health care. The aim of the present study was to explore work-related factors important to health among primary health care employees to increase the knowledge base on how to develop relevant workplace health promotion strategies.

\section{Methods}

\subsection{Setting}

While primary health care systems differ in construction depending on where in the world you live, the primary goal is the same; to provide health care to residents on equal terms, regardless of their age, sex, income or education. Primary health care in Sweden - with public and private health care centers offers tax-funded non-institutional care, and provides citizens with medical treatment, nursing care and rehabilitation services. Various professional teams such as physicians, nurses, psychologists and physiotherapists deliver these services. A cross- sectional, questionnaire study was conducted in public as well as private primary health care centers (PHCCs), in both urban and rural areas. All 26 PHCCs within one health care district in southern Sweden opted to participate.

\subsection{Respondents}

The sample included health care employees from a variety of professional groups: physicians, nurses (registered nurse, assistant nurse), paramedical staff (psychologists, counsellors, occupational therapists, physiotherapists, dieticians), and administrative staff (such as medical secretaries and receptionists). Total $\mathrm{N}=599$. Staffs on long-term sick leave or maternity leave were excluded, as well as all the managers and owners of the PHCCs.

\subsection{Questionnaire and procedure}

The salutogenic perspective formed the basis for the questionnaire and included: health, psychosocial work environment and experiences, recovery, leadership, social climate, reflection and work-life balance. The questionnaire was based on two previously validated and psychometrically tested instruments, SHIS (Salutogenic Health Indicator Scale) measuring indicators of health, e.g. respondents' feelings and experiences of their physical, mental and social well-being [25], and WEMS (Work Experience Measurement Scale) [26]. 
Five sub-indices of WEMS were used (See Table 1). Both instruments were constructed through theoretical analysis of various dimensions of health. Questions on salutogenic work conditions complemented these measures. Apart from a literature review on the relationship between work-related factors and health, these questions were mainly developed through the analyses of five focus group interviews and four individual interviews in seven of the participating PHCCs to secure a high content validity (for results, contact the author). The study can be considered to have high content validity, also due to the evaluation by subject matter experts of whether the questions were essential and useful, i.e. covered all aspects of the theoretical definition of each concept.

For most of the questions, a symmetric Likert-type scale was used, where the respondents specified their level of agreement or disagreement. The statements were positively phrased. The response alternatives ranged from $6=$ totally agree to $1=$ totally disagree . A semantic differential with six steps was used in two of the question groups. Demographic data were also collected.

A pilot study was conducted to examine the face validity of the instruments, i.e., to determine that the questionnaire covered the concept it purported to measure in a comprehensible way. Different professions in primary health care - from health care centers not participating in the main study - completed the questionnaire, while commenting on the questions and their responses to the questions, a method called cognitive think-aloud interviewing [27]. This resulted in some minor changes to the questionnaire. The final questionnaire was distributed in the autumn of 2013.

One of the authors (L.E.) attended work group meetings in the majority of the centers, and the employees completed the questionnaire on the spot. Absent employees were given the questionnaire and a prepaid reply envelope afterwards by the manager. In the remaining centers, the manager distributed the questionnaires to the employees who then individually and anonymously sent in the questionnaire by mail in the prepaid envelope. A single reminder, rather than a series of personal reminders were sent to all employees to maintain confidentiality.

\subsection{Analysis}

The questions on the Salutogenic Health Indicator Scale (SHIS) formed one single index, and five sub-indices were made from the Work Experience Measurement Scale (WEMS). In addition five more indices were constructed and used in the regression analysis. The subject areas, which are presented in Table 1, were primarily chosen on empirical grounds, i.e., drawn from the results of the interview study and theoretically based findings in previous research. Due to different numbers of statements in each index, their values have been transformed to obtain the scale $0-100$, where 0 is the most negative value and 100 the most positive. The reliability, i.e. the internal consistency, of the indices was calculated with the Cronbach's alpha (CA) coefficient. To be accepted as an index, the CA coefficient had to be higher than 0.70 [28]. All the indices were created based on the logical connection between the different question areas, i.e. each question contained several items in the same field, and these items were included in the index based on an optimization of CA. One single question - on work-life balance - accompanied the indices: "I am satisfied with my life situation with regard to worklife balance". A Likert-type scale where $6=$ totally agree and $1=$ totally disagree was used.

A multivariable linear regression model was used to determine which variables were associated with SHIS as an indicator of self-rated health. The relationship between the independent variables was analyzed using bivariate correlation (Table 2). The selection of independent variables to be included in the model was based on correlations, $r>0.40$, (Pearson) between SHIS and the independent variables. The model was adjusted by sex, age and working time ( $>80 \%$ and $\leq 80 \%$ ). To study the impact of different professional groups, four additional regression models were studied. Multi-collinearity of the data was excluded (normal variance inflation factor, VIF) and the residuals were tested and shown to have a normal distribution. A comparison of the impact on SHIS of various levels of recovery outside work (3 groups) and during working hours (3 groups) was tested by one-way ANOVA. In all tests, the significance level was set at 0.05 . Statistical analyses were carried out using SPSS 21.0.

\subsection{Ethics}

Prospective participants were given information, either personally and/or through a written information sheet, about the purpose of the study, the confidentiality of their responses.

Participation was voluntary and participants had a right to withdraw from the study at any time. The study was conducted in agreement with the Swedish Law of Research Ethics, SFS 2003:460, which is 
Table 1

Indices used in the study

\begin{tabular}{|c|c|c|c|c|}
\hline Index & $\begin{array}{c}\text { No. of } \\
\text { statements }\end{array}$ & Scale type & (Examples of) statements ${ }^{\mathrm{a}}$ & $\begin{array}{l}\text { Cronbach's } \\
\text { alpha }\end{array}$ \\
\hline$\overline{\text { SHIS }}$ & 12 & Semantic differential & $\begin{array}{l}\text { In the last } 4 \text { weeks, I have... felt alert/tired, } \\
\text { exhausted; felt happy, optimistic/depressed, sad; } \\
\text { felt well/sick. }\end{array}$ & 0.94 \\
\hline $\begin{array}{l}\text { Supportive working } \\
\text { conditions (WEMS) }\end{array}$ & 7 & Likert-type scale & $\begin{array}{l}\text { We encourage and support each other at work. I get } \\
\text { feedback on the work I do. }\end{array}$ & 0.90 \\
\hline $\begin{array}{l}\text { Work experiences } \\
\text { (WEMS) }\end{array}$ & 6 & Likert-type scale & $\begin{array}{l}\text { I feel that my work is meaningful. I am happy when } \\
\text { I go to work. }\end{array}$ & 0.86 \\
\hline Leadership (WEMS) & 6 & Likert-type scale & $\begin{array}{l}\text { My boss is available when I need him/her. My boss } \\
\text { helps us divide our work in a fair way. }\end{array}$ & 0.92 \\
\hline $\begin{array}{l}\text { Time experience } \\
\text { (WEMS) }\end{array}$ & 3 & Likert-type scale & $\begin{array}{l}\text { I have enough time during my normal working } \\
\text { hours to do my job without time pressure (stress). }\end{array}$ & 0.87 \\
\hline Autonomy (WEMS) & 4 & Likert-type scale & $\begin{array}{l}\text { I decide when to do the various work tasks. I decide } \\
\text { how to do my work. }\end{array}$ & 0.85 \\
\hline Recovery & 4 & Likert-type scale & $\begin{array}{l}\text { I feel I get time for recovery during working hours. I } \\
\text { feel } \\
\text { I get time for recovery outside work. I feel that my } \\
\text { everyday life gives me enough recovery. I feel that } \\
\text { my time spent on getting to work/home from work } \\
\text { gives me recovery. }\end{array}$ & 0.83 \\
\hline Energy at work & 3 & Likert-type scale & $\begin{array}{l}\text { I feel that my job gives me new energy. I feel that } \\
\text { my job gives me more energy than what it takes } \\
\text { from me. I feel that we give each other energy } \\
\text { between co-workers. }\end{array}$ & 0.80 \\
\hline Reflection & 3 & Likert-type scale & $\begin{array}{l}\text { I take time to reflect on work-related events. I have a } \\
\text { good understanding of what gives my job } \\
\text { meaning. Self- reflection helps me see my job as } \\
\text { meaningful. }\end{array}$ & 0.73 \\
\hline $\begin{array}{l}\text { Attributes that } \\
\text { characterize the } \\
\text { workplace }\end{array}$ & 8 & Semantic differential & $\begin{array}{l}\text { Characteristics which reflect my workplace: } \\
\text { positive/negative, safe/unsafe, humble/haughty, } \\
\text { trustful/distrustful, fun/boring, open/closed, } \\
\text { solution oriented/problem oriented, } \\
\text { flexible/inflexible. }\end{array}$ & 0.96 \\
\hline $\begin{array}{l}\text { Relationship with } \\
\text { co-workers }\end{array}$ & 3 & Likert-type scale & $\begin{array}{l}\text { I try to be an inspiration to my co-workers. I feel } \\
\text { that my co-workers trust me. I feel that my } \\
\text { co-workers allow me to be seen and heard. }\end{array}$ & 0.82 \\
\hline
\end{tabular}

${ }^{\mathrm{a}}$ For the previously published index SHIS and sub-indices of WEMS, examples on statements are given. For the new indices all items are presented.

Table 2

Bivariate correlations (Pearson's correlation coefficient) between the independent variables

\begin{tabular}{|c|c|c|c|c|c|c|c|c|c|}
\hline & $\begin{array}{c}\text { Supportive } \\
\text { working } \\
\text { conditions } \\
\text { (WEMS) }\end{array}$ & $\begin{array}{c}\text { Work } \\
\text { experience } \\
\text { (WEMS) }\end{array}$ & $\begin{array}{c}\text { Time } \\
\text { experience } \\
\text { (WEMS) }\end{array}$ & $\begin{array}{l}\text { Attributes that } \\
\text { characterize } \\
\text { the workplace }\end{array}$ & $\begin{array}{l}\text { Relationship } \\
\text { with co- } \\
\text { workers }\end{array}$ & $\begin{array}{l}\text { Energy at } \\
\text { work }\end{array}$ & Recovery & Reflection & $\begin{array}{l}\text { Work-life } \\
\text { balance }\end{array}$ \\
\hline $\begin{array}{l}\text { Supportive working } \\
\text { conditions (WEMS) }\end{array}$ & - & & & & & & & & \\
\hline Work experience (WEMS) & 0.665 & - & & & & & & & \\
\hline Time experience (WEMS) & 0.408 & 0.333 & - & & & & & & \\
\hline $\begin{array}{l}\text { Attributes that characterize } \\
\text { the workplace }\end{array}$ & 0.811 & 0.631 & 0.407 & - & & & & & \\
\hline $\begin{array}{l}\text { Relationship with } \\
\text { co-workers }\end{array}$ & 0.609 & 0.491 & 0.350 & 0.595 & - & & & & \\
\hline Energy at work & 0.597 & 0.607 & 0.426 & 0.641 & 0.538 & - & & & \\
\hline Recovery & 0.410 & 0.371 & 0.512 & 0.400 & 0.387 & 0.551 & - & & \\
\hline Reflection & 0.331 & 0.439 & 0.395 & 0.368 & 0.374 & 0.462 & 0.521 & - & \\
\hline Work-life balance & 0.318 & 0.347 & 0.439 & 0.289 & 0.315 & 0.435 & 0.595 & 0.364 & - \\
\hline
\end{tabular}


Table 3

Respondents by sex, age, profession and working time

\begin{tabular}{lcc}
\hline & $n$ & Percent \\
\hline Sex & & \\
$\quad$ Women & 430 & 86 \\
$\quad$ Men & 68 & 14 \\
Age & & \\
$\quad$ 34 years and younger & 54 & 11 \\
35-54 years & 276 & 55 \\
55 years and older & 170 & 34 \\
Profession & & \\
$\quad$ Physician & 99 & 20 \\
Nurse & 232 & 46 \\
Administrative staff & 83 & 17 \\
$\quad$ Paramedical staff & 86 & 17 \\
Working time & & \\
1-50\% & 44 & 9 \\
51-80\% & 165 & 33 \\
$81-100 \%$ & 288 & 58 \\
\hline
\end{tabular}

${ }^{\mathrm{a}} 100 \%$ working time corresponds to 40 hours/week.

in line with the ethical guidelines of the Helsinki Declaration [29]. The principle of voluntariness was met by the respondents' informed consent to participate in the survey. Precautions were made to ensure the anonymity of participating employees as well as participating PHCCs, and all data was treated confidentially.

\section{Results}

The response rate was $84 \%(n=501)$. The majority of the respondents, $86 \%$, were women, the largest occupational group was nursing $(46 \%)$, and the majority of respondents were between $35-54$ years of age (55\%) (Table 3$)$.

On a scale 0-100 the respondents' mean SHIS value was 66.3 (SD 18.6). There were no significant differences in SHIS scores for sex, age or professional group.

A linear regression model, with the index of SHIS as the dependent variable, showed that recovery had the highest relationship to SHIS $(\beta=0.34)$. Also, experiencing a work-life balance $(\beta=0.25)$ and having positive work experiences $(\beta=0.20)$ were significant predictors of SHIS (Table 4). The total model was statistically significant and explained $52.7 \%$ of the variance. These three variables recovery, work-life balance and work experiences, were also the most important ones in all four professional groups when specific regression models for each group were used (data not shown).

As recovery was related to SHIS as shown in Table 4, the SHIS index for various combinations of recovery during working hours and outside work is shown in Table 5. It is evident that self-rated health (SHIS index) for various combinations of recovery during working hours and outside work was related to higher self-rated health independent of the level of recovery outside work suggesting that not only recovery outside work but also recovery during working hours is related to self-rated health.

\section{Discussion}

This salutogenic-oriented study of primary health care employees showed that recovery, work-life balance and work experiences were all independently related to self-rated health as measured by the Salutogenic Health Indicator Scale (SHIS).

Recovery, measured as a combination of recovery during working hours and outside work, had the highest relationship to respondents' perceived health status. Recovery can be defined as a process of psychophysiological unwinding after effort expenditure. Employees with long working hours have been shown to have more need for recovery from work [30]. A recent study showed that need of satisfaction at work was related to a positive recovery state at the end of the workday [31]. It is contended that if recovery during working hours is inadequate, as most often is the case, a need for recovery after work is particularly vital [9]. Health care staff members are confronted with all kinds of strain throughout the workday, including emotional, physical and cognitive demands. Recovery is essential for a healthy and balanced life and for the ability to stay engaged and recharge personal energy resources [32].

Even though studies have reported a link between recovery and physical and mental conditions, most research has focused on recovery outside work. One study recently described how physical and psychological distance from work and work-related feelings or thoughts is central to the recovery experience [33]. Almost no published studies on recovery during working hours have been reported [34]. However, one study revealed that taking micro-breaks throughout the workday reduced fatigue and increased vitality [35]. Results from a Dutch health care study showed that recovery opportunities (one item on the nine-item scale concerned recovery during working hours), had positive effects on health complaints [36].

Results of the present study showed that recovery during working hours had a substantial impact on respondents' perceived health. However, more 
research is needed to explore recovery during working hours and the implication on different kinds of recovery strategies in the workplace.

A significant relationship between work-life balance and health was found in the current study. This result is supported by the conclusion that work-life balance is of major importance when it comes to workforce retention and other work-related factors in health care settings [37]. For example, in that study [37] nurses and midwifes reported high demands in relation to rewards as well as significant lower quality of life compared to a standard population. The dialectic relationship between working life and private life has been described [4], and the participating nurses highlighted the fact that a good day at work made them better prepared to handle different situations in their private life, and vice versa. Similar results were shown in a study of physicians, where a significant relationship between work, family conflict and job stress, as well as perceived job demands, was found [38]. In line with Kroth et al. [39], one conclusion is that it is essential for managers to support a work-life balance among the employees to create healthy work environments in a health care organization.
In the current study, the third significant variable connected to self-rated health was work experiences. For example, to be able to come to work with joy and to experience work as meaningful and challenging. An essential factor when creating a healthy work environment was that the manager made sure that the employees enjoy their work in a pleasant (fun) atmosphere [39]. Experiencing work as challenging and stimulating was directly related to employee health status in the present study. This is in line with previous studies concerning job satisfaction, motivation and positive reinforcement $[15,40]$. A good work environment has positive effects on the individual, their feelings about being useful, competent and enthusiastic about their work is crucial to retention.

Work should be seen as the positive resource it can be, as work is closely associated with the individual's health. A healthy workplace is essential to gaining the most energy from employees [39]. These findings correspond well with the verified relationship between health promotion and well-being, which several literature reviews have brought to light [41, 42]. Apart from the current study in primary health care, studies in hospitals have shown that health care settings contain many positive characteristics,

Table 4

Results from a multivariable linear regression model with the SHIS index as the dependent variable. Adjusted by sex, age and working time

\begin{tabular}{lcccr}
\hline & $\begin{array}{c}\text { Standardized } \\
\text { coefficients } \\
\text { beta }(\beta)\end{array}$ & $\begin{array}{c}\text { Unstandardized } \\
\text { coefficients }(\mathrm{B}) \\
(95 \% \mathrm{CI})\end{array}$ & $p$ & VIF \\
\hline Recovery & 0.34 & $0.90(0.65,1.15)$ & 0.000 & 2.26 \\
Work-life balance & 0.25 & $2.39(1.61,3.18)$ & 0.000 & 1.68 \\
Work experience (WEMS) & 0.20 & $0.47(0.25,0.68)$ & 0.000 & 2.24 \\
Attributes that characterize the workplace & 0.08 & $0.10(-0.05,0.26)$ & 0.195 & 3.49 \\
Energy at work & 0.07 & $0.26(-0.11,0.62)$ & 0.166 & 2.39 \\
Supportive working conditions (WEMS) & -0.07 & $-0.12(-0.33,0.08)$ & 0.245 & 3.60 \\
Relationship with co-workers & 0.05 & $0.12(-0.09,0.32)$ & 0.260 & 1.89 \\
Reflection & 0.03 & $0.12(-0.24,0.47)$ & 0.523 & 1.61 \\
Time experience (WEMS) & 0.01 & $0.03(-0.20,0.26)$ & 0.898 & 1.55 \\
\hline
\end{tabular}

Adjusted $\mathrm{R}^{2}=0.527$; ANOVA $(\mathrm{F}=44.5 ; p=0.000)$; Factors presented in order of their contribution to the model. $\mathrm{VIF}=$ variance inflation factor. Variables not included in the model: leadership (WEMS), autonomy (WEMS).

Table 5

Mean (SD) for the SHIS index for various combinations of the variables recovery during working hours and recovery outside work

\begin{tabular}{|c|c|c|c|c|c|}
\hline & \multicolumn{5}{|c|}{ Recovery during working hours ${ }^{\mathrm{a}}$} \\
\hline & & Group 5-6 & Group 3-4 & Group 1-2 & $\mathrm{p}^{\mathrm{b}}$ \\
\hline \multirow[t]{3}{*}{ Recovery outside work ${ }^{\mathrm{a}}$} & Group 5-6 & $82.9(13.8)(n=76)$ & $74.4(13.9)(n=104)$ & $66.6(15.3)(n=59)$ & 0.000 \\
\hline & Group 3-4 & $68.2(19.0)(n=10)$ & $62.5(14.1)(n=103)$ & $56.8(16.9)(n=84)$ & 0.013 \\
\hline & Group 1-2 & $-(n=0)$ & $-(n=1)$ & $43.6(9.7)(n=35)$ & na \\
\hline
\end{tabular}

${ }^{\mathrm{a}}$ For the statements I feel I get time for recovery during working hours and I feel I get time for recovery outside work, respectively, three groups where made from the response alternatives ranging from totally agree (6) to totally disagree (1): group 5-6 (highest), group 3-4 and group 1-2 (lowest). ${ }^{b}$ One-way ANOVA to test the hypothesis of a relationship between SHIS and recovery during working hours in groups with different report of recovery outside work. 
for example to experience meaningfulness, autonomy and social support at work [26]. These factors are essential to future work towards good health for all employees.

One strength of the present study is the high participation rate, which is essential for drawing valid conclusions. A number of steps were taken to increase intrinsic motivation among the potential participants. Lately, it has been considered important to include motivation theories in survey research [43]. All comprising efforts in the implementation of the study, the salutogenic perspective of the survey, and the promise to each PHCC that the results of therespective PHCC would be reported back as a foundation for subsequent interventional efforts at the health care center, were all motivational. Since the response rate was 84 percent, the potential dropout effects on the findings are considered small.

Another strength is the high validity. Two validated instruments were used, SHIS [25] and WEMS [26] which were complemented by questions developed in a procedure from individual and focus group interviews via an expert panel to a pilot study to ensure high content and face validity. All indices used had high reliability in terms of their internal consistency. Apart from the high response rate and the high validity, the representative selection of primary health care centers and their employees contributed to reduce selection bias.

Finally, a strong factor was the level of SHIS (mean 66.3). This was similar to what has previously been reported for hospital employees [25]. This suggests that the sample in the current study is highly representative of the working experience of health care professionals.

In every work-related study, the effect of selection bias must be kept in mind [44]. As an individual must be relatively healthy to be employable, the employees in any work force are supposedly healthier than the general population. The interpretation of the results should include these considerations. Results were obtained from self-report which may introduce some information bias; on the other hand, the short recall time in the questionnaire may reduce the bias. Social desirability in responding may introduce some bias as well.

We chose to study self-rated health in relation to work environment and the employees' own experiences related to work. Confounders like sex, age and working time were adjusted for, but other factors such as life-style, household composition and ongoing morbidity were not considered, which can be seen as a limitation. Another limitation is the cross-sectional design of the study, which precludes drawing any causal conclusions. On the other hand, being one of the first studies ever in primary health care focusing on work experiences and health from a salutogenic perspective, it is possible to draw important conclusions regarding the relationship between health and work experiences, even if causality could not be confirmed.

\section{Conclusion}

To the best of our knowledge there are few published studies on salutogenic work factors, underlining the importance of researching this area. There were three areas of special importance to employee health, to which the management and the employees should pay close attention: recovery, work-life balance and work experiences. It appears that recovery during working hours is of great value in relation to high self-rated health, regardless of recovery outside work. These findings could form the basis for further study into how to use a salutogenic approach when developing workplace health promotion in other workplace contexts. However, more research is needed to explore different recovery strategies in the workplace.

\section{Acknowledgments}

The study was funded by Kristianstad University with financial support from the Scania Regional Council and the Association of General Practitioners in Sweden.

\section{Conflict of interest}

The authors declare that they have no conflict of interest.

\section{Authors' contributions}

LE was the main author of the manuscript and involved in all aspects of the study. BH, GE and IA contributed in the design and planning of the study, the data interpretation and writing of the manuscript. GE and IA also contributed in performing the statistical analyses. All authors read and approved the final manuscript. 


\section{References}

[1] European Network for Workplace Health Promotion (ENWHP). Luxembourg Declaration on Workplace Health Promotion in the European Union. 2007 [cited 2016 Sept 22]. Available from: http://www.enwhp.org/fileadmin/rsdokumente/dateien/Luxembourg_Declaration.pdf

[2] World Health Organization. Ottawa charter for health promotion: An International Conference on Health Promotion, the move towards a new public health. Ottawa: World Health Organization; 1986.

[3] Whitehead D. Workplace health promotion: The role and responsibility of health care managers. J Nurs Manag 2006; 14(1):59-69.

[4] Bringsén Å, Andersson HI, Ejlertsson G, Troein M. Exploring workplace-related factors and health from a salutogenic perspective. Results from a focus group study among health care workers in Sweden. Work 2012;42:403-14.

[5] Siegrist J. Reducing social inequalities in health: Workrelated strategies. Scand J Public Health 2002;30:49-53.

[6] Wressle E, Samuelsson K. High job demands and lack of time. A future challenge in occupational therapy. Scand J Occup Ther 2014;21(6):421-28.

[7] Sonnentag S, Kuttler I, Fritz C. Job stressors, emotional exhaustion, and need for recovery: A multi-source study on the benefits of psychological detachment. J Vocal Behav 2010;76:355-65.

[8] Van Steenbergen E, Ellemers N. Is managing the workfamily interface worthwile? Benefit for employee health and performance. J Organ Behav 2009;30:617-42.

[9] Geurts SAE, Sonnentag S. Recovery as an explanatory mechanism in the relation between acute stress reactions and chronic health impairment. Scand J Work Environ Health 2006;32:482-92.

[10] Maslach C, Schaufeli WB, Leiter MP. Job burnout. Annu Rev Psychol 2001;52:397-422.

[11] Peterson U, Demerouti E, Bergström G, Samuelsson M, Asberg M, Nygren A. Burnout and physical and mental health among Swedish healthcare workers. J Adv Nurs 2008;62(1):84-95.

[12] Wieclaw J, Agerbo E, Mortensen PB, Bonde JP. Risk of affective and stress related disorders among employees in human service professions. Occup Environ Med 2006; 63(5):314-9.

[13] García-Rodríguez A, Gutiérrez-Bedmar M, BellónSaameño JÁ, Muñoz-Bravo C, Fernández-Crehuet Navajas J. Psychosocial stress environment and health workers in public health: Differences between primary and hospital care. Aten Primaria 2015;47(6):359-66.

[14] Coomber B, Barriball KL. Impact of job satisfaction components on intent to leave and turnover for hospital-based nurses: A review of the research literature. Int J Nurs Stud 2007;44(2):297-314.

[15] Josephson M, Lindberg P, Voss M, Alfredsson L, Vingård E. The same factors influence job turnover and long spells of sick leave - a 3-year follow up of Swedish nurses. Eur J Public Health 2008;18:380-5.

[16] Galdikiene N, Asikainen P, Balciu S, Suominen T. Do nurses feel stressed? A perspective from primary health care. Nurs Health Sci 2014;16:327-34.

[17] Teles MA, Barbosa MR, Vargas AM, Gomes VE, Ferreira EF, Martins AM, Ferreira RC. Psychosocial work conditions and quality of life among primary health care employees:
A cross sectional study. Health Qual Life Outcomes 2014; 12:72. doi: 10.1186/1477-7525-12-72

[18] Virtanen M, Virtanen P, Oksanen T, Kivimäki M, Pentti J, Vahtera J. Work stress and health in primary health care physicians and hospital physicians. Occup Environ Med 2008;65(5):364.

[19] Siegrist J, Shackelton R, Link C, Marceau L, von dem Knesebeck O, McKinlay J. Work stress of family care physicians in the US, UK and German health care systems. Soc Sci Med 2010;71:298-304.

[20] Kumar S. Review. Burnout and doctors: Prevalence, prevention and intervention. Healthcare 2016;4:37. doi:10.3390/ healthcare 4030037

[21] Lindberg P, Vingård E. Indicators of healthy work environments - a systematic review. Work 2012;41(Suppl 1): 3032-8

[22] Eriksson M, Lindström B. Antonovsky's Sense of Coherence Scale and it's relation with quality of life: A systematic review. J Epid Comm Health 2007;61:938-44.

[23] Antonovsky A. Unraveling the mystery of health. How people manage stress and stay well. San Francisco: Jossey-Bass Inc; 1987.

[24] Nilsson P, Andersson HI, Ejlertsson G, Troein M. Workplace health resources based on sense of coherence theory. Int J Workplace Health Manag 2012;5(3):156-67.

[25] Bringsén Å, Andersson HI, Ejlertsson G. Development and quality analysis of the Salutogenic Health Indicator Scale (SHIS). Scand J Public Health 2009;37:13-9.

[26] Nilsson P, Bringsén Å, Andersson HI, Ejlertsson G. Development and quality analysis of the Work Experience Measurement Scale (WEMS). Work 2010;35:153-61.

[27] Tourangeau R. Cognitive Science and Survey Methods. In Jabine T, Straf M, Tanur J, Tourangeau R (eds). Cognitive aspects of survey methodology: Building a bridge between disciplines. Washington DC: National Academy Press; 1984: pp. 73-100.

[28] Bland J, Altman D. Statistics notes: Cronbach's alpha. BMJ 1997;314:572.

[29] World Medical Association. World Medical Association Declaration of Helsinki: Ethical principles for medical research involving human subjects. Jama 2013;310(20): 2191-4.

[30] Jansen NWH, Kant IJ, van Amelsvoort LGPM, Nijhuis FJN, van den Brand A. Need for recovery from work: Evaluating short-term effects of working hours, patterns and schedules. Ergonomics 2003;46:664-80.

[31] Van Hooff MLM, Geurts SAE. Need satisfaction and employees' recovery state at work: A daily diary study. J Occup Health Psychol 2015;20:377-87.

[32] Sonnentag S, Binnewies C, Mojza EJ. "Did you have a nice evening?" A day-level study on recovery experiences, sleep and affect. J Appl Psychol 2010;93:674-84.

[33] Sonnentag S, Fritz C. Recovery from job stress: The stressor-detachment model as an integrative framework. J Organ Behav 2015;36:72-103.

[34] de Bloom J, Kinnunen U, Korpela K. Exposure to nature versus relaxation during lunch breaks and recovery from work: Development and design of an intervention study to improve workers' health, well-being, work performance and creativity. BMC Public Health 2014;14:488.

[35] Zacher H, Brailsford HA, Parker SL. Micro-breaks matter: A diary study on the effects of energy management strategies on occupational well-being. J Vocat Behav 2014;85(3): 287-97. 
[36] van Veldhoven MJPM, Sluiter JK. Work-related recovery opportunities: Testing scale properties and validity in relation to health. Int Arch Occup Environ Health 2009;82: 1065-75.

[37] Schluter PJ, Turner C, Huntington AD, Bain CJ, McClure RJ. Work/life balance and health: The nurses and midwives e-cohort study. Int Nurs Rev 2011;58:28-36.

[38] Mache S, Bernburg M, Groneberg DA, Klapp BF, Danzer G. Work family conflict in its relations to perceived working situation and work engagement. Work 2016;53(4):859-69.

[39] Kroth M, Boverie P, Zondlo J. What managers do to create healthy work environments. J Adult Educ 2007;36:1-12.

[40] Liukkonen V, Virtanen P, Vahtera J, Suominen S, Sillanmäki L, Koskenuuo M. Employment trajectories and changes in sense of coherence. Eur J Public Health 2010;20:293-8.
[41] Kuoppala J, Lamminpaa A, Husman P. Work health promotion, job wellbeing, and sickness absences - a systematic review and meta-analysis. J Occup Environ Med 2008;50: 1216-27.

[42] Soler RE, Leeks KD, Razi S, Hopkins DP, Griffith M, Aten, A, et al. A systematic review of selected interventions for worksite health promotion - the assessment of health risks with feedback. Am J Prev Med 2010;38:237-62.

[43] Wenemark M, Vernby A, Norberg AL. Can incentives undermine intrinsic motivation to participate in epidemiologic surveys? Eur J Epidemiol 2010;25:231-5.

[44] Li CY, Sung PC. A review of the healthy worker effect in occupational epidemiology. Occup Med 1999;49(4):225-9. 